VIS

Revista do Programa de Pós-graduação em Arte da UnB

\title{
O Paradoxo da Natureza-morta
}

Hanneke Grootenboer ${ }^{1}$

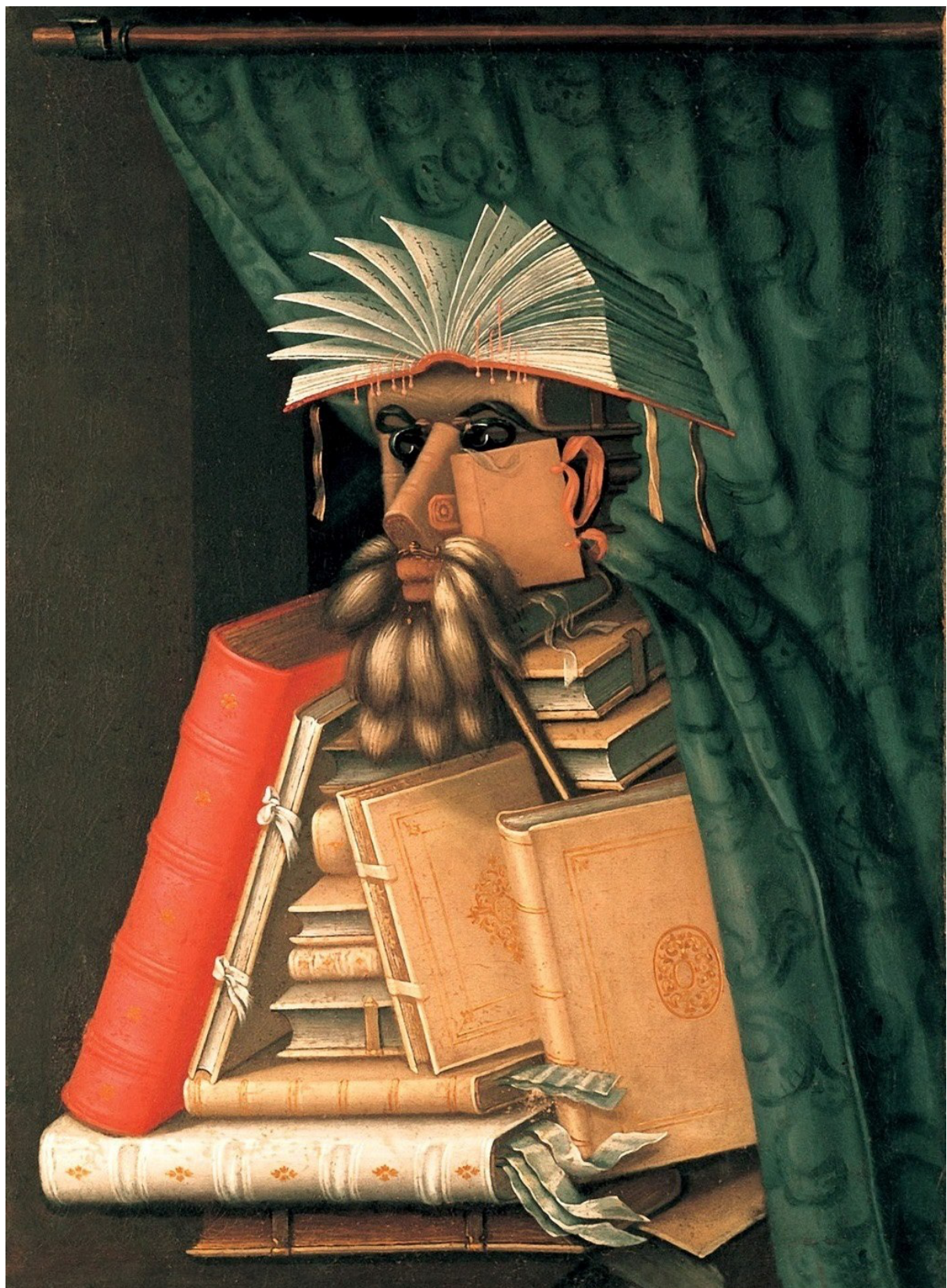

1 Tradução de Raisa Ramos de Pina. "The Paradox of Still Life". In: Oxford Art Journal, 34.3 (2011), p. 486-488. 
A pintura de natureza-morta nasceu como gênero internacional e independente por volta de 1600. Nenhum país pode reivindicar o título de precursor do gênero e nenhum artista pode ser considerado o primeiro pintor de natureza-morta, porque suas manifestações podem ser encontradas em tradições pictóricas de toda a Europa - desde as pinturas flamengas marianas do século $\mathrm{XV}$, às bodegas espanholas e figuras de capitetos, passando pelos livros de história natural e pelas pinturas italianas de mercados de carne. De diversas formas, essas imagens compartilham a representação de alimentos, flores, vasos e outros objetos mundanos, insignificantes, que compõem as obras. $\mathrm{O}$ que aconteceu por volta de 1600 é que esses objetos prosaicos de repente se tornaram o ponto central de uma única pintura.

Um dos primeiros teóricos de natureza-morta, Gérard de Lairesse, em 1707, fulminou a aparente insignificância, superficialidade e falta de complexidade técnica das naturezas-mortas, argumentando apaixonadamente que artistas não deveriam fazê-las. A disciplina História da Arte, em seus primeiros anos de existência, reproduziu os discursos precursores sobre natureza-morta, subestimando o gênero. Por décadas, a obra monumental de Charles Sterling Still Life Painting: From Antiquity to the Twentieth Century (1952) e Dutch Still Life Painting in the Seventeenth Century, de Ingvar Bergström (traduzido do sueco em 1956) eram duas das poucas referências sobre o tema. Entretanto, desde a publicação do provocativo Looking at the Overlooked: Four Essays on Still Life Painting, de Norman Bryson (1990), o interesse pela natureza-morta vem crescendo gradualmente. A principal tese de Bryson, de que a natureza-morta se manteve pouco teorizada, tem sido derrubada pelo fluxo constante de trabalhos publicados nos últimos vinte anos, incluindo pesquisas 
importantes, como as de Sybille Ebert-Schifferer e Claus Grimm. Somamse a elas, trabalhos mais específicos como o Still Life and Trade in the Dutch Golden Age, de Julie Berger Hochstrasser (2007); o catálogo da exposição Painter to the Court of Marie Antoinette, de Anne Vallayer-Coster (editado por Eik Kahng e Marianne Roland Michel, 2002); The Body of Raphaelle Peale: Still Life and Selfhood, 1812-1824, de Alexander Nemerov (2001); e o brilhante estudo de Victor Stoichita sobre as origens da natureza-morta, The Self-Aware Image (1998). A esta lista, inclui-se mais dois novos itens: Arcimboldo: Visual Jokes, Natural History and Still-Life Painting, de Thomas DaCosta Kaufmann (University Chicago Press, 2009), e Caterpillage: Reflections on Seventeenth-Century Dutch Still Life Painting, de Harry Berger Jr. (Fordham University Press, 2011). Os dois livros oferecem ao leitor resultados de mais de trinta e cinco anos de análises e reflexões sobre pintura, e se apresentam como discussões de alto nível, repletos de detalhes intrigantes.

À luz do pedido de Bryson de se teorizar mais sobre naturezamorta, Berger e Kaufmann podem ser compreendidos como opositores no atual campo de estudos sobre os primórdios da arte moderna. Como o próprio título indica, Berger oferece reflexões sobre o motivo pouco explorado da lagarta nas naturezas-mortas do século XVII, no intuito de questionar a abordagem dominante de então, que relaciona o bicho à imagem de vanitas. Por outro lado, Kaufmann questiona as origens do gênero a partir dos retratos criados com elementos inanimados ${ }^{2} \mathrm{de}$ Arcimboldo (1526-1593), essencialmente com o objetivo de restaurar os

\footnotetext{
${ }^{2}$ Geralmente flores, frutos e vegetais. A autora se refere a esses retratos como "composite heads", uma expressão que, traduzida fielmente para o português, parece perder sua força e a potência do trabalho do artista italiano, que será mais detalhado à frente. Optou-se, portanto, em traduzir a expressão inglesa como "retratos criados com elementos inanimados" (N.T.). 
jogos visuais do artista, dando-lhes seu lugar legítimo na história da arte e na ciência. Este lugar legítimo, como se revela, não se refere a uma reflexão teórica, e a relutância de Kaufmann em ir por essa linha é palpável ao longo do livro. Este talvez seja o único aspecto lamentável do estudo, que poderia propiciar a base para pesquisas futuras sobre Arcimboldo.

O livro de Kaufmann se debruça maciçamente sobre diversas publicações dos últimos trinta e cinco anos sobre Arcimboldo. Argumentos que ouvimos antes - como por exemplo, os retratos com elementos inanimados terem sido criados não na Milão do fim da década de 1550, cidade-natal do artista, mas na corte central européia dos Habsburgos, onde ele iniciou sua carreira como retratista (ou melhor, copiador de retratos); ou sobre o profundo interesse do milanês por história natural - foram agora comprovados e fortemente sustentados por uma documentação visual e verbal. O livro defende que os retratos de Arcimboldo tinham a intenção de alimentar o pensamento das cortes de Maximiliano II e Rodolfo II e, portanto, eles deveriam ser analisados como compilações para os estudos naturais mais sérios do artista. Além disso, essas pinturas espirituosas poderiam ser comparadas com o mundo às avessas do Elogio à Loucura (1511), de Erasmo de Rotterdam, que revela estruturas profundas do pensamento ao longo da figura retórica de reversão satírica.

Após um detalhamento minucioso, no primeiro capítulo do livro, das origens de Arcimboldo na Lombardia e das origens da produção das primeiras composições da celebrada série Quatro Estações no segundo capítulo, a narrativa de Kaufmann decola, conduzindo o leitor pelos círculos já conhecidos em que o artista se movimentou durante a corte. 
Nela, o italiano colaborou com poetas, astrônomos e médicos, além de participar de eventos e festivais temáticos em que suas pinturas pareciam oferecer um modelo estético a ser seguido. Para se ter uma ideia, em 1571, durante a procissão de comemoração de um casamento real dos Habsburgos, cortesãos apareceram vestidos com estampas semelhantes à Água, retrato feito com peixes por Arcimboldo. Na ocasião, o próprio imperador Maximiliano, líder de estado, vestiu-se de Inverno (considerado o líder das estações), reencenando a composição do retrato do imperador, finalizado pelo artista em 1563.

A maior contribuição do livro de Kaufmann são os resultados do profundo interesse do artista pela representação da natureza e a pesquisa implacável do autor sobre os estudos naturais de Arcimboldo, presente nos capítulos 5 e 6. Como demonstra, durante os anos do artista na corte, foram produzidos numerosos desenhos de animais e estudos botânicos, a maioria deles provavelmente retratada "após a morte". Essa discussão se apresenta como testemunha do livro: Kaufmann demonstra que Arcimboldo era considerado um especialista em história natural. Seus estudos de plantas e desenhos de mamíferos e pássaros eram considerados tão importantes que, em 1582, o imperador o enviou à Alemanha, em uma missão para registro de todas as espécies possíveis de animais do Velho e do Novo Mundo. No contexto de seus estudos naturais, os retratos criados com elementos inanimados, especialmente as séries Estações e Elementos, ganharam nova ressonância. Apesar de parecerem elementos arranjados aleatoriamente como se fosse brincadeira, as composições resumem um modo de se estudar história natural dentro 
de uma Kunstkammer ${ }^{3}$ antes do rigor das classificações científicas. Além disso, Kaufmann reivindica que esses retratos devem ser analisados como parte de uma projeção da majestade imperial. Como mostra Inverno, retrato de Maximiliano, e Vertumnus, retrato de Rodolfo II, o imperador comandava o corpo político assim como fazia com o microcosmo de suas coleções de arte. Estas, por sua vez, refletiam o macrocosmo do universo.

Kaufmann argumenta que o investimento de Arcimboldo em natureza é uma das razões pelas quais o artista é um dos progenitores do gênero de natureza-morta, uma ideia já cunhada por Sterling e melhor explorada nos capítulos 7 e 8 . Discorrendo contra os acadêmicos que consideravam Arcimboldo principalmente um maneirista cujos jogos visuais ou scherzi se aproximam do fantástico e do grotesco, Kaufmann sugere que essas pinturas, especialmente por elas não convidarem a uma leitura estável, criam um jogo único, uma forma que corporifica o paradoxo interno das pinturas de natureza-morta. Tal jogo pode ser visto, já explica a teoria de Roland Barthes, como duas das figuras retóricas do discurso mais vislumbradas: a metáfora e a metonímia. Rodeado por poetas e outros humanistas da corte, o artista era (alguns vão dizer) um poeta ele próprio.

Apesar de Kaufmann discordar do argumento de Bathes, ou melhor, do tipo de crítica que ele motiva - que, além de outras coisas, analisa Arcimboldo como um precursor do surrealismo -, os capítulos 3 e 4 (sobre poesia, sabedoria e jogos sérios) mostram como os contemporâneos de Arcimboldo comprovam a tese barthesiana: Gregorio Comanini, teórico amigo do artista, chamava seus trabalhos de alegorias aprendidas; outro escritor, Gian Paolo Lomazzo, determinou que o

${ }^{3}$ Gabinete de curiosidades ou, em uma tradução literal, câmara de arte. (N.T). 
grotesco era uma maneira de expressar conceitos em formas visuais. Entretanto, Kaufmann discute as forças do fantástico e do grotesco como opostas àquelas do estudo científico, encontrando na noção dos jogos sérios um último paradoxo. Ao invés de explorar mais profundamente as complexidades do paradoxo e as diversas maneiras pelas quais essa figura une diferentes conceitos sem fundi-los, Kaufmann se prende parcialmente no argumento contra os acadêmicos que, de alguma forma, não levam os jogos de Arcimboldo suficientemente a sério, porque enfatizam mais fortemente os aspectos do fantástico. $\mathrm{O}$ autor sugere que o que ele considera paradoxal é o jogo do fantástico ou do grotesco de impedir qualquer pensamento sério.

Além disso, a maioria dos trabalhos de Arcimboldo, assim como a recepção de seus contemporâneos, demonstra que é precisamente o jogo da deformidade que suscita o paradoxo interno, quase na mesma medida em que o paradoxo faz emergir a noção do jogo. Esse duplo paradoxo é perturbado pelo poema inspirado em Vertumnus, de Comanini, que escreve como se falasse para o retrato de Rodolfo II: "Quem quer que você seja, olhe para mim/ Uma estranha e deformada imagem/ Com uma gargalhada nos seus lábios/ Que brilha em seus olhos/ E estampa na sua cara/ Com felicidade de romance/ À vista de um novo monstro". Neste poema, em um último gesto de sagacidade, o paradoxo ultrapassa a moldura da pintura quando o eu/você reverso na primeira sentença deixa claro que é tanto o eu olhando para o retrato quanto o retrato olhando para o eu. Esse reverso culmina no momento em que a pintura se torna, literalmente, o espelho da natureza, quando o retrato reflete uma gargalhada ao olhar de um novo monstro, que se revela o próprio narrador do poema. Esse tipo de jogo - de duplicar e reverter o interno 
inerente, ou melhor, o constitutivo da imagem - não é, surpreendentemente, trabalhado por Kaufmann. Um exemplo ainda mais literal desse tipo de jogo é a inversão dos retratos de Arcimboldo que, quando virados de cabeça para baixo, revelam meros vegetais em um pote.

É nessas pinturas, discutidas no último capítulo, que as raízes da natureza-morta se tornam mais evidentes, mas é também aqui que o argumento de Kaufmann sobre as mensagens dos jogos visuais se torna levemente repetitivo e superficial. A questão de se saber exatamente qual a mensagem séria que as alegorias aprendidas de Arcimboldo transmitem não é realmente respondida quando Kaufmann afirma que os jogos foram criados para instruir e entreter. Além disso, as obras, como caprichos da arte, apresentariam um argumento visual que contradiria outras ideias de imitação, ou que elas simbolizariam a prosperidade do imperador do momento. Essas respostas, entretanto, não são aprofundadas. $\mathrm{Na}$ discussão substancial do paradoxo interno das naturezas-mortas, da qual as imagens de Arcimboldo são exemplos fabulosos, é uma surpresa que a discussão influente de Stoichita sobre o nascimento do gênero como resultado de um gesto de inversão tenha sido omitida. Como Stoichita já demonstrou, as naturezas-mortas surgiram primeiramente nos versos de retratos; a inversão dos retratos para revelar a natureza-morta marca não apenas a emergência de um novo gênero, mas também o surgimento de uma pintura como comentário de si mesma.

$\mathrm{O}$ argumento de Stoichita poderia ter ajudado a trazer à tona o comentário de Arcimboldo sobre práticas miméticas mais vigorosamente do que é realmente trazido. Apesar de o livro defender de maneira convincente que o conhecimento mundano incorporado nos retratos 
criados com elementos inanimados é tanto poético quanto científico, tanto espirituoso quanto profundo, Kaufmann não permite que as composições continuem a encenar um papel animado e importante na produção de significado de séculos porvir. Para Kaufmann, a sagacidade arcimboldesca é fortemente preservada, trancada nas imagens, não lançada como inspiração em potencial, por exemplo, para o surrealismo. Além disso, a ideia de que essas imagens poderiam verdadeiramente exemplificar ou mapear estruturas complexas, linguísticas ou não, para os estudantes e acadêmicos de hoje, ou até mesmo para a crítica ou para filósofos - uma questão para a qual, a meu ver, os retratos com elementos inanimados convidam tão claramente - é uma linha de pensamento que Kaufmann, pelo menos neste trabalho, argumenta veementemente contra, afirmando que é uma ideia inadequada e implausível. De fato, por essa perspectiva, as pinturas fascinantes de Arcimboldo devem ser vistas exclusivamente como o ponto final de diversos pensamentos filosóficos e científicos do século XVI, mas nunca como uma abertura para novas ideias.

A essa luz, o magistral ensaio Caterpillage, de Berger, pode ser considerado o oposto completo do livro de Kaufmann, no sentido de que ele se preocupa precisamente com a interpretação suscitada resultante daquilo que Berger chama de captura alegórica. Neste trabalho deslumbrante e emocionante, o autor se aproxima cada vez mais do paradoxo interno da natureza-morta ao declarar que, ao invés de ser uma reverência à natureza, a alegoria a deprecia. Motivos clássicos como os caracóis e as lagartas das pinturas de flores do século XVII, ou mais especificamente, das representações, por exemplo, de natureza de Joris Hoefnagel, foram tradicionalmente interpretados como agentes de decadência, ressaltando uma sensação permanente de transitoriedade, 
lenta, mas inevitável. Profundamente cético à iconografia dominante de vanitas, Berger sugere que, ao invés da interpretação recorrente, vanitas é o "McGuffin" da natureza-morta, um termo que ele empresta de Alfred Hitchcock. Um "McGuffin" é um objeto ou um elemento da trama que é apresentado como particularmente significante, que ocupa a mente do espectador enquanto o filme continua a rodar: é uma peça do entendimento que o espectador alegremente abraça como algo compreendido do quebra-cabeça apresentado, enquanto o suspense é construído e mantém a tensão.

Nos últimos anos, é impressionante quão domesticada (alguns podem dizer preguiçosa) se tornou a atitude dos tradicionais historiadores da arte de considerar o tema de vanitas como memento mori na naturezamorta; de fato, o argumento agora está por toda a parte e Berger está certo em apontar o quanto essa interpretação se tornou um pretexto confortável no lugar de mensagens inquietantes que podem estar escondidas nas esquinas escuras da natureza-morta. É na exposição dessas esquinas escuras que outro sentido da natureza-morta aparece: não de perecibilidade da vida, mas de estrago; não de um aviso contra a decadência, mas de má-fé; não de memento mori, mas de rapacidade. Em uma série de pequenos comentários, Berger revela as correntes existentes por debaixo do padrão das figuras alegóricas. Apoiando-se em Hochstrasser, o autor aponta que embaixo de uma imagem positiva e assertiva de comidas exóticas e troféus do comércio, espreitam narrativas desconhecidas sobre produção e distribuição de mantimentos, sobre a corrupção, a opressão e a escravidão. Ele discute o balanço delicado mantido nas naturezas-mortas, as ameaças de colapso e a desintegração nunca apresentadas nos amontoados de comidas, além da violência em 
escala reduzida que os insetos provocam nos arrebatadores arranjos de flores. Analisadas como vanitas-estilo-McGuffin, Berger argumenta brilhantemente que até mesmo na natureza retratada por um dos mais proeminentes precursores de natureza-morta, Joris Hoefnagel (1542-1601), assim como nos estudos mais tardios sobre lagartas de Maria Sybilla Merian (1647-1717), percebemos como essas imagens são verdadeiros campos de batalha nos quais insetos dissimuladamente inocentes representam formas discretas de agressão, de ganância e de violência, embora em uma escala microscópica. Como Berger finalmente argumenta, é na tensão entre a sedução das alegorias e suas mensagens não confiáveis, entre a sua força cativante e sua interpretação fluida, que encontramos momentos de terror.

O estudo histórico sólido de Kaufmann e o trabalho imaginativo de Berger podem ocupar polos opostos no que se refere ao modo com que conduzem suas atitudes frente à pesquisa tradicional e a uma metodologia investigativa (e, consequentemente, a uma ideologia); apesar disso, não seria sábio preferir um ao outro. Uma combinação aproximada entre o histórico e o teórico ofereceria - ainda - o trabalho acadêmico mais excitante sobre os primórdios da arte moderna (Stoichita é um excelente exemplo, apesar de raro), mas na falta disso, nós lucraríamos mais ao ler Kaufmann e Berger em suas totalidades, como eu mesma fiz para manter o diálogo entre suas posições, relacionando-as entre si e, consequentemente, mantendo vivo o interno e vital paradoxo da naturezamorta. 